\title{
Are Readmissions After THA Preventable?
}

\author{
Douglas S. Weinberg MD, Matthew J. Kraay MD, Steven J. Fitzgerald MD, \\ Vasu Sidagam MD, Glenn D. Wera MD
}

Received: 27 July 2016/Accepted: 31 October 2016/Published online: 11 November 2016

(C) The Association of Bone and Joint Surgeons ( 2016

\begin{abstract}
Background Readmissions after total joint arthroplasty have become a key quality measure in elective surgery in the United States. The Affordable Care Act includes the Hospital Readmission Reduction Program, which calls for reduced payments to hospitals with excessive readmissions. This policy uses a method to determine excess readmission ratios and calculate readmission payment adjustments to hospitals, however, it is unclear whether readmission rates are an effective quality metric. The reasons or conditions associated with readmission after elective THA have been well established but the extent to
\end{abstract}

\footnotetext{
Each author certifies that he, or a member of his immediate family, has no funding or commercial associations (eg, consultancies, stock ownership, equity interest, patent/licensing arrangements, etc) that might pose a conflict of interest in connection with the submitted article.

All ICMJE Conflict of Interest Forms for authors and Clinical Orthopaedics and Related Research ${ }^{\mathbb{R}}$ editors and board members are on file with the publication and can be viewed on request.

Each author certifies that his institution approved the human protocol for this investigation, that all investigations were conducted in conformity with ethical principles of research, and that informed consent for participation in the study was obtained.
}

Electronic supplementary material The online version of this article (doi:10.1007/s11999-016-5156-x) contains supplementary material, which is available to authorized users.

D. S. Weinberg $(\bowtie)$, M. J. Kraay, S. J. Fitzgerald, V. Sidagam

Department of Orthopaedic Surgery, University Hospitals,

Cleveland Medical Center, Case Western Reserve University,

11100 Euclid Avenue, Cleveland, OH 44106, USA

e-mail: Dsw56@case.edu

G. D. Wera

MetroHealth Medical Center, 2500 MetroHealth Drive,

Cleveland, OH 44109, USA which readmissions can be prevented after THA remains unclear.

Questions/purposes (1) Are unplanned readmissions after THA associated with orthopaedic or medical causes? (2) Are these readmissions preventable? (3) When during the course of aftercare are orthopaedic versus medical readmissions more likely to occur?

Methods We retrospectively evaluated all 1096 elective THAs for osteoarthritis performed between January 1, 2011 and June 30, 2014 at a major academic medical center. Of those, 69 patients $(6 \%)$ who met inclusion criteria were readmitted in our healthcare system within 90 days of discharge after the index procedure during the study period. Fifty patients were readmitted within 30 days of discharge after the index procedure (5\%). We defined a readmission as any unplanned inpatient or observation status admission to the hospital spanning at least one midnight. A panel of physicians not involved in the care of these patients used available criteria and existing consensus guidelines to evaluate the medical records, radiographs, and operative reports to identify whether the underlying reason for readmission was orthopaedic versus medical. They subsequently were classified as either nonpreventable or potentially preventable readmissions, based on any care that may have occurred during the index hospitalization. To make such determinations, consensus specialty society guidelines were used whenever possible for each readmission diagnosis.

Results A total of 50 of 1096 patients (5\% of those who underwent THA during the period in question) were readmitted within 30 days and 69 of $1096(6 \%)$ were readmitted within 90 days of their index procedures. Thirty-one patients were readmitted for orthopaedic reasons $(31 / 69 ; 45 \%)$ and 38 of 69 were readmitted for medical reasons $(55 \%)$. Three readmissions (three of $69 ; 4 \%$ ) were identified as potentially preventable. Of these potentially preventable readmissions, 
one was orthopaedic (hip dislocation) and two were medical. Thirty-day readmissions were more likely to be orthopaedic than 90-day readmissions (odds ratio, 4.06; 95\% CI, 1.1813.96; $\mathrm{p}=0.026)$.

Conclusions Using a panel of expert reviewers, available existing criteria, and consensus methodology, it appears only a small percentage of readmissions after THA are potentially preventable. Orthopaedic readmissions occur earlier during the postoperative course. Currently, existing policies and readmission penalties may not serve as valuable external quality metrics. The readmission rates in our study may represent the threshold for expected readmission rates after THA. Future studies should enroll larger numbers of patients and have independent review panels in efforts to refine criteria for what constitutes preventable readmissions.

Level of Evidence Level III, therapeutic study

\section{Introduction}

Owing to the Patient Protection and Affordable Care Act, healthcare systems have been under increased scrutiny to provide value-based care [9]. The increasing number of THAs performed in the United States has created substantial expense across the US healthcare system. Consequently, healthcare payers are currently exploring and using cost-saving avenues associated with this widely used procedure. Specifically, the Centers for Medicare and Medicaid Services have begun focusing on 30-day hospital readmissions as a quality measure by instituting payment adjustment policies for readmissions [14, 29, 41, 47].

Thirty-day readmissions after THA have been reported to occur in $4 \%$ and $11 \%$ of patients $[6,10,20,22,31,32,48,50,61]$. Considerable efforts have been devoted toward identifying patient-specific factors associated with readmission after THA. Well-established factors associated with readmission after THA include increased age, sex (men are more likely to be readmitted than women), obesity, increasing length of hospital stay, revision surgery, and decreased distance to the hospital [3, 24, 52, 60, 64]. Racial and socioeconomic disparities in readmission rates are currently being investigated [40]. Incentives to reduce readmissions after THA may indirectly decrease access to care for patients with these risk factors; it has been suggested that these patients may be denied care by certain hospital systems attempting to control costs [64]. It would be especially relevant, therefore, to identify the actual etiology of the readmission and whether aspects of patient care during the index hospitalization could be modified to prevent such readmissions.

Furthermore, some authors have called into question the appropriateness of readmission rate as a standalone measurement of quality [18, 36]. In an increasingly restricted payer environment, we sought to determine whether readmissions after THA were potentially preventable through any intervention that could have been performed during the index hospitalization for THA.

Accordingly, we designed a study to answer the following questions: (1) Are unplanned readmissions after THA associated with orthopaedic or medical causes? (2) Are these readmissions potentially preventable? (3) When during the course of aftercare are orthopaedic and medical readmissions more likely to occur?

\section{Materials and Methods}

After institutional review board approval, a quality database at a single major academic healthcare institution was queried. We retrospectively evaluated all 1096 elective THAs for osteoarthritis performed between January 1, 2011 and June 30, 2014 at University Hospitals, Cleveland Medical Center. Search criteria were performed according to International Classification of Diseases, $9^{\text {th }}$ Revision (ICD-9) and Diagnosis-related Group (DRG) codes (Fig. 1). Records of the patients who were readmitted to our healthcare system within 30 and 90 days from the index procedure were analyzed in detail. Patients undergoing revision arthroplasty or bilateral primary THAs were excluded, as were those performed by surgeons not fellowship trained in total joint arthroplasty. Other exclusion criteria were patients who were younger than 25 years at the time of surgery and patients who received THA for fracture. All surgeries were performed by one of five highvolume, fellowship-trained arthroplasty surgeons.

All patients underwent methicillin-resistant and sensitive Staphylococcus aureus (MRSA/MSSA) screening and prevention and a formal preoperative evaluation by the department of anesthesia and perioperative medicine. MRSA and MSSA screening involved patients swabbing a saline moistened swab in both nares and rubbing on the septum. Each swab was sent to the microbiology laboratory and cultured for Staphylococcus aureus. Cultures with positive growth were analyzed for antibiotic sensitivities. Patients who were positive for MRSA or MSSA underwent a standard decolonization treatment protocol consisting of chlorhexidine body wash applied by the patient the day before surgery, and intranasal mupirocin ointment. MRSA and MSSA colonization were present in two of $69(3 \%)$ and 15 of $69(21 \%)$ patients, respectively.

The electronic medical record for each readmission was reviewed by a panel of researchers, including two orthopaedic surgeons and a physician specializing in perioperative medicine. In an effort to control for assessor bias, the members of the research panel were not involved 


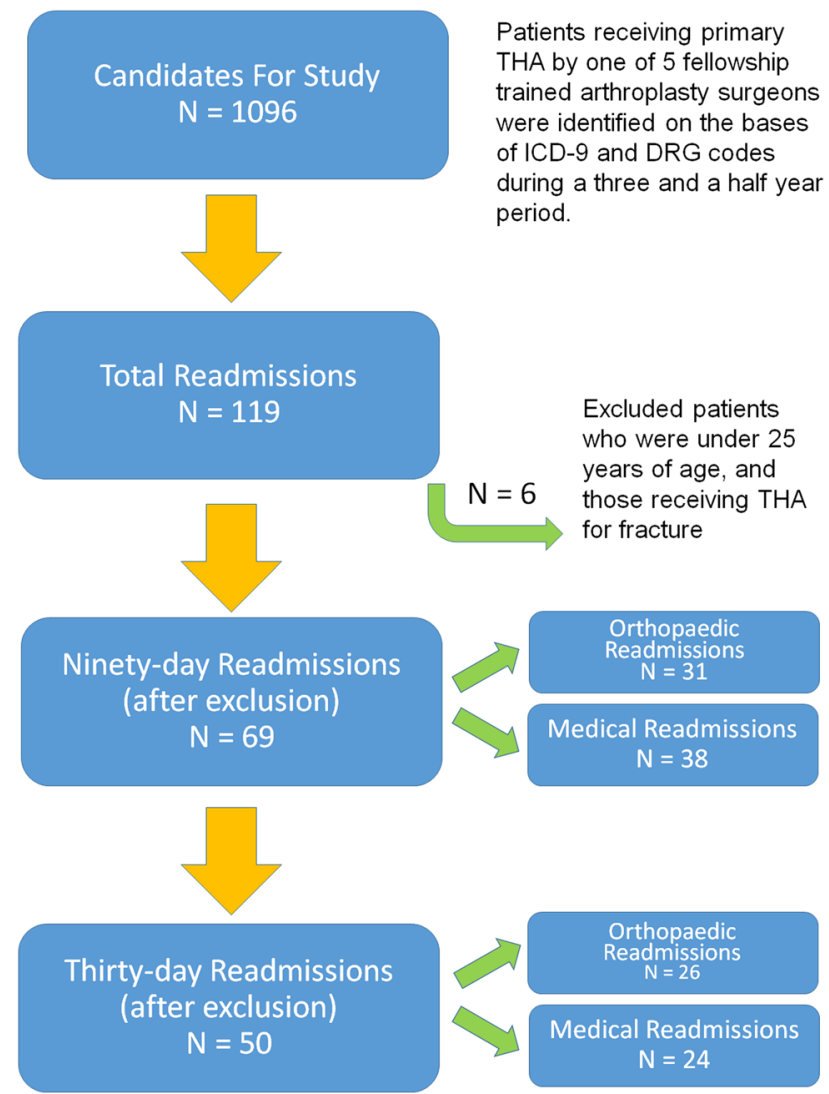

Fig. 1 One thousand ninety-six elective THAs were reviewed at a major academic medical center. Readmissions were reviewed in detail, and categorized as either orthopaedic or medical.

in the original patient care. However, the reviewers were from the same institution as this was deemed necessary to provide complete access to the requisite hospital files and databases; providing an external reviewer unrestricted access to the entire hospital record (inpatient electronic medical record, laboratory data, nursing notes, daily progress notes, anesthesia records, radiographic records) was not deemed to be practical. The complete hospital encounters for the index arthroplasty and the readmission encounter were reviewed. Medical records were reviewed by the research panel and included evaluation of operative reports, physician notes, inpatient vital signs, laboratory values, radiographic imaging, medications, and medical history. We defined a readmission as any unplanned inpatient or observation status admission to the hospital spanning at least one midnight [55]. To determine how readmissions were related to the timing of surgery, readmissions were categorized as 30- or 90-day readmissions based on the timing of readmission and were determined to be of orthopaedic or medical etiology [35].

Orthopaedic readmissions were defined using criteria adapted from Kurtz et al. [35], as readmissions stemming from surgeons' decisions or technical errors such as
Table 1. Types of readmissions grouped according to cause

\begin{tabular}{|c|c|}
\hline $\begin{array}{l}\text { Reasons for orthopaedic/ } \\
\text { technical readmission }\end{array}$ & Reasons for medical readmission \\
\hline $\begin{array}{l}\text { Periprosthetic fracture } \\
\text { Joint infection } \\
\text { Hematoma } \\
\text { Dislocation } \\
\text { Subsidence without fracture }\end{array}$ & $\begin{array}{l}\text { Atrial fibrillation } \\
\text { Appendicitis } \\
\text { Cellulitis } \\
\text { Chest pain, not otherwise specified } \\
\text { Clostridium difficile infection } \\
\text { Dehydration } \\
\text { Diverticular disease } \\
\text { Ileus } \\
\text { Myocardial infarction } \\
\text { Cholelithiasis } \\
\text { Nausea } \\
\text { Nephrolithiasis } \\
\text { Pain control } \\
\text { Pneumonia } \\
\text { Alcohol withdrawal } \\
\text { Sepsis } \\
\text { Small bowel obstruction } \\
\text { Seroma } \\
\text { Sickle cell crisis } \\
\text { Subarachnoid hemorrhage } \\
\text { Urinary tract infection } \\
\text { Vaginal bleeding }\end{array}$ \\
\hline
\end{tabular}

improper prosthesis size or alignment, including periprosthetic fracture, dislocation, or infection. Medical readmissions were defined as readmissions stemming from either medical diagnoses such as myocardial infarction, chest pain, or urinary tract infection or medical decision errors such as unrecognized illness or premature discharge (Table 1) [2].

Panel members were asked to determine if readmissions were potentially preventable through some intervention that could have occurred during the index hospitalization. A literature search of PubMed, Google Scholar, and Web of Science was performed to identify specialty society guidelines for applicable diagnoses, where available (Appendix 1. Supplemental material is available with the online version of $\mathrm{CORR}^{\mathbb{R}}$ ). The American College of Surgeons National Surgical Quality Improvement Program criteria for postoperative occurrences were used for applicable diagnoses (Appendix 2. Supplemental material is available with the online version of $\mathrm{CORR}^{\circledR}$ ) $[1-3,7,15,23-25,43,45,52-54,56-58,60,63,64]$.

Potentially preventable readmissions therefore were defined as conditions or diagnoses that could have been avoided through some intervention during the index 
Table 2. Individual patients readmitted after elective THA

\begin{tabular}{|c|c|c|c|c|}
\hline Gender & Age (years) & Reason for readmission & Potentially preventable readmission? & Readmission day \\
\hline $\mathrm{F}$ & 76 & Atrial fibrillation & No & 6 \\
\hline M & 81 & Atrial fibrillation & No & 10 \\
\hline M & 77 & Atrial fibrillation & No & 10 \\
\hline $\mathrm{F}$ & 74 & Atrial fibrillation/CHF & No & 56 \\
\hline $\mathrm{F}$ & 67 & Appendicitis & No & 55 \\
\hline M & 43 & Appendicitis & No & 57 \\
\hline M & 59 & Cellulitis & No & 13 \\
\hline M & 56 & Cellulitis & No & 7 \\
\hline $\mathrm{F}$ & 70 & Chest pain not otherwise specified & No & 10 \\
\hline M & 79 & Chest pain not otherwise specified & Yes $^{*}$ & 24 \\
\hline M & 63 & Cholelithiasis & No & 32 \\
\hline $\mathrm{F}$ & 88 & Clostridium difficile & No & 43 \\
\hline M & 55 & Dehydration & No & 3 \\
\hline M & 48 & Dislocated hip & Yes $^{\dagger}$ & 2 \\
\hline $\mathrm{F}$ & 65 & Dislocated hip & No & 24 \\
\hline $\mathrm{F}$ & 62 & Dislocated hip & No & 1 \\
\hline M & 68 & Dislocated hip & No & 15 \\
\hline $\mathrm{F}$ & 83 & Diverticular disease & No & 32 \\
\hline $\mathrm{F}$ & 83 & Diverticular disease & No & 76 \\
\hline $\mathrm{F}$ & 76 & Diverticular disease & No & 1 \\
\hline $\mathrm{F}$ & 67 & Hematoma & No & 52 \\
\hline $\mathrm{F}$ & 52 & Hematoma & No & 19 \\
\hline $\mathrm{F}$ & 54 & Hematoma & No & 10 \\
\hline $\mathrm{F}$ & 87 & Hematoma & No & 6 \\
\hline $\mathrm{F}$ & 88 & Hematoma & No & 14 \\
\hline $\mathrm{F}$ & 75 & Hematoma & No & 31 \\
\hline $\mathrm{F}$ & 66 & Hematoma & No & 17 \\
\hline $\mathrm{F}$ & 50 & Hematoma & No & 9 \\
\hline $\mathrm{F}$ & 69 & Hematoma & No & 5 \\
\hline M & 90 & Hematoma & No & 7 \\
\hline M & 67 & Hematoma & No & 21 \\
\hline $\mathrm{F}$ & 42 & Hematoma & No & 7 \\
\hline M & 56 & Hematoma & No & 11 \\
\hline M & 58 & Hematoma/component exchange & No & 3 \\
\hline M & 69 & Hematoma & No & 10 \\
\hline $\mathrm{F}$ & 48 & Ileus & No & 19 \\
\hline $\mathrm{F}$ & 66 & Ileus & No & 2 \\
\hline $\mathrm{F}$ & 62 & Joint infection & No & 4 \\
\hline $\mathrm{F}$ & 76 & Joint infection & No & 24 \\
\hline M & 54 & Joint infection & No & 19 \\
\hline $\mathrm{F}$ & 63 & Joint infection & No & 8 \\
\hline $\mathrm{F}$ & 81 & Myocardial infarction & No & 6 \\
\hline M & 70 & Nephrolithiasis & No & 10 \\
\hline $\mathrm{F}$ & 65 & Pain control & No & 25 \\
\hline $\mathrm{F}$ & 68 & Pain control & No & 81 \\
\hline $\mathrm{F}$ & 17 & Pain control & No & 7 \\
\hline $\mathrm{F}$ & 16 & Pain control & No & 2 \\
\hline M & 51 & Pain control/withdrawal & No & 2 \\
\hline
\end{tabular}


Table 2. continued

\begin{tabular}{|c|c|c|c|c|}
\hline Gender & Age (years) & Reason for readmission & Potentially preventable readmission? & Readmission day \\
\hline $\mathrm{F}$ & 75 & Periprosthetic fracture & No & 23 \\
\hline $\mathrm{F}$ & 75 & Periprosthetic fracture & No & 41 \\
\hline M & 67 & Periprosthetic fracture & No & 19 \\
\hline $\mathrm{F}$ & 67 & Periprosthetic fracture & No & 29 \\
\hline $\mathrm{F}$ & 70 & Periprosthetic fracture & No & 5 \\
\hline $\mathrm{F}$ & 67 & Periprosthetic fracture & No & 16 \\
\hline $\mathrm{F}$ & 78 & Pneumonia & No & 5 \\
\hline $\mathrm{F}$ & 65 & Pneumonia & No & 2 \\
\hline $\mathrm{F}$ & 56 & Pneumonia & No & 61 \\
\hline M & 69 & Pneumonia & No & 18 \\
\hline $\mathrm{F}$ & 21 & Pneumonia/sickle cell crisis & No & 2 \\
\hline $\mathrm{F}$ & 69 & Postoperative pain & No & 14 \\
\hline M & 59 & Sepsis (Streptococcus viridans) & No & 6 \\
\hline $\mathrm{F}$ & 77 & Seroma & No & 22 \\
\hline $\mathrm{F}$ & 29 & Sickle cell crisis & No & 27 \\
\hline $\mathrm{F}$ & 83 & Small bowel obstruction & No & 16 \\
\hline M & 77 & Small bowel obstruction & No & 63 \\
\hline $\mathrm{F}$ & 77 & Subarachnoid hemorrhage & No & 73 \\
\hline $\mathrm{F}$ & 53 & Subsidence without fracture & No & 40 \\
\hline $\mathrm{F}$ & 72 & Urinary tract infection & Yes $^{*}$ & 9 \\
\hline $\mathrm{F}$ & 37 & Vaginal bleeding & No & 56 \\
\hline
\end{tabular}

* The patient was discharged with nonspecific chest pain, presented less than 24 hours later to the emergency department with similar complaints, although was not readmitted at this time; however, 24 days later the patient again presented with chest pain and was readmitted for a full cardiac consultation; ${ }^{\dagger}$ the patient was readmitted with a hip dislocation after a technically complex primary THA; component position and fixation were suboptimal; the patient, who had a history of urinary tract infections, was discharged with subjective dysuria and later readmitted with a urinary tract infection that potentially might have been preventable; $\mathrm{F}=$ female; $\mathrm{M}=$ male; $\mathrm{CHF}=$ congestive heart failure .

hospitalization based on criteria published elsewhere or practice guidelines. Readmissions resulting from fracture were said to be nonpreventable if there was adequate bone stock with appropriate implant sizing and alignment. Hematomas were deemed nonpreventable in cases in which the appropriate intensity of deep vein thrombosis chemoprophylaxis was used; however, the form of prophylaxis for deep vein thrombosis varied among surgeons, and tranexamic acid was not used consistently during this time [38]. Infections were determined to be nonpreventable if the patients received MRSA screening and prevention measures and appropriate prophylactic antibiotics [26, 46]. Dislocations were determined to be nonpreventable if the prosthesis size, alignment, and offset were appropriate on postoperative radiographs [37]. Subsidence was deemed nonpreventable if the implant size and alignment were appropriate on the postoperative radiograph. Given that there are no universal criteria available, subsidence was judged on an individual basis [25].

There were a total of 1096 primary THAs with 119 total readmissions during the study period $(11 \%)$, with 69 of these readmissions occurring within the first 90 days $(6 \%)$.
All analyses were performed using SPSS Version 23. 0 software program (IBM Inc, Armonk, NY, USA). All data were analyzed for skewness and kurtosis. Q-Q plots were generated to assess normality in distribution. Descriptive statistics were calculated, and univariate comparisons between categorical variables were performed with Fisher's exact test. Odds ratios were calculated. Agreement between and among reviewers was assessed with the Cohen's Kappa statistic. Significance was set at a probability of 0.05 or less.

\section{Results}

Of the 119 total readmissions, 69 met inclusion criteria. There were 31 of $69(45 \%)$ readmissions of orthopaedic etiology and 38 of $69(55 \%)$ readmissions of medical etiology among the 90-day readmissions. There was unanimous agreement among reviewers (DSW, VS, GDW). The primary reviewer (DSW) assessed intraobserver reliability with a 2-year period between reviews, and again found unanimous agreement. 
We identified three of 69 total (4\%) potentially preventable readmissions; one was orthopaedic in etiology (hip dislocation attributable to failure of acetabular component) and two were medical. The hip dislocation was a 30-day readmission after primary THA in a patient in whom the acetabular component positioning and fixation were determined to be suboptimal by the study panel. Among the medical etiologies of preventable readmissions, one patient was readmitted with a urinary tract infection, which potentially could have been detected during the index hospitalization. A second patient was readmitted with chest pain. These readmissions occurred at 9 and 24 days after the index procedures (Table 2). There were 31 of $69(45 \%)$ orthopaedic readmissions. Of these, there were: six periprosthetic fractures (six of $31 ; 20 \%$ ), five of which occurred after falls, one after a motor vehicle collision; 16 hematomas (16 of 31; 52\%); four infections (four of 31 ; $13 \%$ ), four dislocations (four of $31 ; 13 \%$ ); and one instance of femoral component subsidence without fracture (one of $31 ; 3 \%$ ). A complete summary of the entire readmission data is presented (Table 2).

There were 50 readmissions within 30 days (50/69; $72 \%$ ), and 69 total readmissions within 90 days. Thirty-day readmissions were more likely to be the result of orthopaedic etiology than 90-day readmissions: $52 \%$ during first 30 days (26/50) versus $21 \%$ during Days 31 to 90 (four of 19; odds ratio, 4.06; 95\% CI, 1.18-13.96; $\mathrm{p}=0.026)$.

\section{Discussion}

Hospital readmission after total joint arthroplasty has profound implications on patient care and reimbursement patterns [63]. However, there is limited information available to justify whether certain readmissions may be preventable through any intervention that could have occurred during the index hospitalization [13, 59]. Joynt and Jha [28] suggested that readmission rates are a poor marker of hospital performance, as the primary drivers of variability in 30-day readmissions are patient- and community-related. As they explained, such factors are difficult for hospitals or surgeons to change. Under the Affordable Care Act, the current scheme which penalizes hospitals for readmission rates, has the potential to deny access to care to certain individuals or regions where patients are more likely to be readmitted [28]. Existing data fail to establish whether readmissions after THA are in any way indicative of surgeon performance. This raises the question regarding whether readmission rates are a true reflection of quality even when risk-adjusted. Rather, it may be more appropriate to focus on preventable readmissions to minimize cost and permit appropriate access to care during the perioperative period [50]. Therefore, we thought it would be especially pertinent to perform a study that emphasized a detailed review of individual subject records as opposed to large registry data to answer the following questions: (1) Are unplanned readmissions after THA associated with orthopaedic or technical or medical causes? (2) Are these readmissions potentially preventable? (3) When during the course of aftercare are orthopaedic or technical versus medical readmissions more likely to occur?

This study is best interpreted in the context of its limitations. Most importantly, the decision for hospital readmission often can be complex, and it is possible that modifiable or preventable risk factors for readmission might not be evident in the electronic medical record. The panel was tasked with determining whether readmissions were potentially preventable. Although objective specialty society guidelines were used whenever possible, there was a subjective component involved; however, the panel showed unanimous agreement. Another limitation in this and other studies is that we were able to identify only patients readmitted in our own hospital network. As is true with any orthopaedic complication, it is possible that patients were readmitted elsewhere owing to geographic, social, or economic reasons. However, much of what we know about perioperative surgical complications is based on records such as the National Surgical Quality Improvement Program (NSQIP ${ }^{\circledR}$ ), the National Inpatient Sample, or other large quality databases [2, 28, 29]. Such databases have been used to report readmission trends with time, which were not analyzed in our study. Some authors have suggested databases provide only moderately reliable information relevant to readmission diagnoses [30]. However, our detailed review of the medical record for each readmission was able to mitigate the shortcoming of large databases. Along those lines, this may raise concern for assessor bias, however, Saucedo et al. [51] suggested that analyses that rely on physician-reviewed diagnoses provide up to $25 \%$ more-accurate information than those relying strictly on database coding information. Although it was not possible to have an individual from another institution review the complete medical record, we still suggest that our data are some of the most accurate. Although any review of internal data should raise concern regarding assessor bias, this was mitigated in our study by having research personnel perform data review. Moreover, physicians were not asked to review their own complications and the panel of researchers was not involved in any of the initial patient care. Other limitations include findings restricted to the geographic location of our hospital network. ICD-9 and DRG codes were used to identify patients for inclusion. Tranexamic acid was used inconsistently during the study period, and surgeons used various anticoagulation protocols. Although our study was aimed to identify actions that could have been performed at the 
index hospitalization, it is unknowable whether any of these actions specifically caused any of the complications - a similar limitation of other outcomes studies.

These data showed that unplanned readmission after THA occurs for orthopaedic and medical reasons. The distinctions for orthopaedic-related readmissions were based on the recent study by Kurtz et al. [35]. They showed a higher prevalence of orthopaedic etiologies in 30-day readmissions and medical etiologies for 90-day readmissions, especially regarding infection. These associations with readmission, regardless of its relevance to the primary THA, result in financial penalties for the surgeon and healthcare system [29]. Bozic et al. [9] performed a comprehensive analysis of episode-of-care payments for total joint arthroplasty and found that postdischarge care accounted for $37 \%$ of total episode of payments and may be as much as $81 \%$ for unplanned readmissions. Unplanned readmissions within 30 days of a THA may not be reimbursable under many bundled payment models and may contribute to $11 \%$ of all postdischarge costs [9]. Bosco et al. [8] and Kiridly et al. [33] concluded that the direct cost of unplanned readmissions averages USD 17,000. They noted that hospital margins would need to be more than $4 \%$ for primary THAs to account for the cost of nonreimbursed readmissions. Considerable efforts have been devoted toward establishing risk factors for hospital readmissions, with many institutions establishing and scrutinizing their protocols aimed toward reduction of unplanned readmissions [16, 20, 31, 32, 39, 44, 50, 61, 64].

We found that very few readmissions potentially could have been prevented by any intervention that might have been performed during the index hospitalization. Of the potentially preventable readmissions we examined, only one patient was determined to have a readmission attributed to orthopaedic etiology. However, it was a technically complex primary THA complicated by acetabular component migration and dislocation resulting from suboptimal alignment and inadequate fixation [5]. To our knowledge, there has been limited research performed on the effect of component position on readmission rate, although suboptimal component position has been linked to instability after THA and eventual reoperation [12, 42, 62]. When dislocation does occur owing to component position, hospital readmission may not occur; many instances of primary dislocation are reduced in the emergency department without formal admission. Although the majority of hospital readmissions in this study were not preventable based on our analysis of their index procedure, hematoma was the most common orthopaedic readmission diagnosis. However, it is again important to note that tranexamic acid was not used consistently during the study period. Jorgenson et al. [27] recently reviewed 557 readmissions after THA or TKA, and found that $6 \%$ of readmissions were potentially preventable based on failure to optimize medical risk factors. These findings are in contrast to inpatient readmissions for medical patients, with data suggesting that between $9 \%$ and $48 \%$ of readmissions were potentially preventable [2, 4]. We agree with other authors [64] who have suggested that further separating the risk factors-and causes-of medical and surgical readmissions are needed. The discrepancy in these readmission rates might be because a total joint arthroplasty is a planned procedure with preoptimized risk factors, as opposed to most medical admissions which occur unexpectedly.

Data from this study suggest that orthopaedic readmissions are more likely to occur earlier during the postoperative course, whereas readmissions of medical etiology are more likely to occur later during the postoperative course. As Joynt and Jha [28] reported, this is especially important in determining the root cause of hospital readmissions to help hospitals and payers allocate associated penalties. These data are in accord with an earlier study that suggested 30-day readmissions may be the more-sensitive measure for establishing readmission benchmark data [11]. Epstein [17] stated that the more time that elapses from the index procedure to the readmission event, the more time that is allowed for a separate, unrelated event to occur that may influence the readmission rate. Zmistowski et al. [64] reported a 90-day readmission rate of $5 \%$ and concluded that "zero tolerance" events are not easily preventable in this period. A recent meta-review by Ramkumar et al. [50] showed that the overall pooled readmission rate after THA was $6 \%$ at 30 days and $8 \%$ at 90 days. Similarly, median 30- and 90-day readmission rates are $6 \%$ and $11 \%$, respectively, according to the Medicare $100 \%$ national hospital claims database [34]. The readmission rate at our institution was slightly lower, although comparable to other high-volume joint replacement centers that have reported 30-day readmission rates between $5 \%$ and $6 \%[16,20,31,32,39,44,50,61]$. Although some authors have reported 30-day readmission rates as low as $2 \%$, most of these results are for carefully selected patients with nonconventional approaches [19]. Furthermore, reviews of major databases such as the NSQIP $^{\circledR}$ have suggested 30 -day readmission rates are between $4 \%$ and $6 \%$ nationwide [49].

However, on the basis of these data, a reasonable conclusion may be that readmission after THA reflects appropriate access to care and penalty thresholds associated with readmission are an overly aggressive policy to reduce the cost of THA. Although some have suggested that readmissions are a false quality measure for hospital performance [21], we instead argue that such data provide physicians and administrators valuable feedback, albeit on many issues that might be influenced by external factors. 
The total cost of hospital care gives insight into how profound the financial consequences of hospital readmission can be $[10,48]$. Although this type of analysis suggests that most readmissions after THA are likely not preventable, this information might be useful for internal quality metrics, as hospitals and clinicians strive to optimize their hospital networks. We agree with Joynt and Jha [28] who suggested that since many of the driving factors behind readmissions are region-specific, larger public health initiatives may be necessary. Subjecting hospital networks to external penalties, however, may be a misuse of such data. Calculating risk-adjusted models for orthopaedic-specific factors is an important next step.

This study was intended to determine whether readmissions could be prevented by an intervention during the index hospitalization. As such, the readmission rate of approximately 5\% identified in this cohort of patients may represent the threshold or expected rate of readmissions using a conventional, hospital-based arthroplasty service at a major academic medical center. Further reductions in readmissions after THA might be possible through enhanced patient selection, prehospital optimization measures, and enhanced posthospital coordination of care. The study adds to the growing body of evidence suggesting that the existing penalties currently in place for readmissions after THA might not be valid markers of standardized quality. Future studies may consider independent assessment of readmission data on a larger scale, and should especially focus on elimination of perioperative blood loss and appropriate chemoprophylaxis for deep vein thrombosis prevention and efforts to optimize pre- and posthospital care.

\section{References}

1. American Psychiatric Association. Diagnostic and Statistical Manual of Mental Disorders. Arlington, VA: American Psychiatric Publishing; 2013.

2. Auerbach AD, Kripalani S, Vasilevskis EE, Sehgal N, Lindenauer PK, Metlay JP, Fletcher G, Ruhnke GW, Flanders SA, Kim C, Williams MV, Thomas L, Giang V, causes of readmissions in a national cohort of general medicine patients. JAMA Intern Med. 2016;176:484-493.

3. Avram V, Petruccelli D, Winemaker M, de Beer J. Total joint arthroplasty readmission rates and reasons for 30-day hospital readmission. J Arthroplasty. 2014;29:465-468.

4. Benbassat J, Taragin M. Hospital readmissions as a measure of quality of health care: advantages and limitations. Arch Intern Med. 2000;160:1074-1081.

5. Biedermann R, Tonin A, Krismer M, Rachbauer F, Eibl G, Stockl B. Reducing the risk of dislocation after total hip arthroplasty: the effect of orientation of the acetabular component. J Bone Joint Surg Br. 2005;87:762-769.

6. Bohl DD, Shen MR, Kayupov E, Della Valle CJ. Hypoalbuminemia independently predicts surgical site infection, pneumonia, length of stay, and readmission after total joint arthroplasty. J Arthroplasty. 2016;31:15-21.
7. Bone RC, Balk RA, Cerra FB, Dellinger RP, Fein AM, Knaus WA, Schein RM, Sibbald WJ. Definitions for sepsis and organ failure and guidelines for the use of innovative therapies in sepsis: the ACCP/SCCM Consensus Conference Committee. American College of Chest Physicians/Society of Critical Care Medicine. Chest. 1992;101:1644-1655.

8. Bosco JA 3rd, Karkenny AJ, Hutzler LH, Slover JD, Iorio R. Cost burden of 30-day readmissions following Medicare total hip and knee arthroplasty. J Arthroplasty. 2014;29:903-905.

9. Bozic KJ, Ward L, Vail TP, Maze M. Bundled payments in total joint arthroplasty: targeting opportunities for quality improvement and cost reduction. Clin Orthop Relat Res. 2014;472:188193.

10. Clement RC, Derman PB, Graham DS, Speck RM, Flynn DN, Levin LS, Fleisher LA. Risk factors, causes, and the economic implications of unplanned readmissions following total hip arthroplasty. J Arthroplasty. 2013;28(8 suppl):7-10.

11. Cram P, Lu X, Kaboli PJ, Vaughan-Sarrazin MS, Cai X, Wolf $\mathrm{BR}, \mathrm{Li}$ Y. Clinical characteristics and outcomes of Medicare patients undergoing total hip arthroplasty, 1991-2008. JAMA. 2011;305:1560-1567.

12. Cutrera NJ, Pinkas D, Toro JB. Surgical approaches to the acetabulum and modifications in technique. J Am Acad Orthop Surg. 2015;23:592-603.

13. Dailey EA, Cizik A, Kasten J, Chapman JR, Lee MJ. Risk factors for readmission of orthopaedic surgical patients. $J$ Bone Joint Surg Am. 2013;95:1012-1019.

14. Department of Health and Human Services. Modifications to the HIPAA Privacy, Security, Enforcement, and Breach Notification Rules Under the Health Information Technology for Economic and Clinical Health Act and the Genetic Information Nondiscrimination Act; Other Modifications to the HIPAA Rules. Federal Register. 2013;78:5565-5702.

15. Dharmarajan K, Hsieh AF, Lin Z, Bueno H, Ross JS, Horwitz LI, Barreto-Filho JA, Kim N, Bernheim SM, Suter LG, Drye EE, Krumholz HM. Diagnoses and timing of 30-day readmissions after hospitalization for heart failure, acute myocardial infarction, or pneumonia. JAMA. 2013;309:355-363.

16. Elmallah RK, Cherian JJ, Amin H, Jauregui JJ, Pierce TP, Mont MA. Readmission rates in patients who underwent total hip arthroplasty. Surg Technol Int. 2015;27:215-217.

17. Epstein AM. Revisiting readmissions: changing the incentives for shared accountability. N Engl J Med. 2009;360:1457-1459.

18. Fischer C, Lingsma HF, Marang-van de Mheen PJ, Kringos DS, Klazinga NS, Steyerberg EW. Is the readmission rate a valid quality indicator? A review of the evidence. PLoS One. 2014;9:e112282.

19. Gofton W, Chow J, Olsen KD, Fitch DA. Thirty-day readmission rate and discharge status following total hip arthroplasty using the supercapsular percutaneously-assisted total hip surgical technique. Int Orthop. 2015;39:847-851.

20. Halawi MJ, Vovos TJ, Green CL, Wellman SS, Attarian DE, Bolognesi MP. Current evidence does not support Medicare's 3day rule in primary total joint arthroplasty. Am J Orthop (Belle Mead NJ). 2015;44:E370-372.

21. Hawk PB. Ready or not: hospital value-based purchasing poised to transform healthcare reimbursement model and introduce new fraud targets under the False Claims Act. Annals Health Law. 2013;22:43.

22. Healy WL, Iorio R, Clair AJ, Pellegrini VD, Della Valle CJ, Berend KR. Complications of total hip arthroplasty: standardized list, definitions, and stratification developed by The Hip Society. Clin Orthop Relat Res. 2016;474:357-364.

23. Hechenbleikner EM, Makary MA, Samarov DV, Bennett JL, Gearhart SL, Efron JE, Wick EC. Hospital readmission by method of data collection. J Am Coll Surg. 2013;216:1150-1158. 
24. Huddleston JI, Wang Y, Uquillas C, Herndon JH, Maloney WJ. Age and obesity are risk factors for adverse events after total hip arthroplasty. Clin Orthop Relat Res. 2012;470:490-496.

25. Issa K, Pivec R, Wuestemann T, Tatevossian T, Nevelos J, Mont MA. Radiographic fit and fill analysis of a new second-generation proximally coated cementless stem compared to its predicate design. J Arthroplasty. 2014;29:192-198.

26. Jain N, Johnson T, Morehouse L, Rogers S, Guleri A, Dunkow P. MRSA \& MSSA screening for elective lower limb arthroplasty. Bone Joint J Orthop Proc Suppl. 2013;95:205.

27. Jorgensen CC, Petersen MA, Kehlet H; Lundbeck Foundation Centre for Fast-Track Hip and Knee Replacement Collaborative Group. Preoperative prediction of potentially preventable morbidity after fast-track hip and knee arthroplasty: a detailed descriptive cohort study. BMJ Open. 2016;6:e009813.

28. Joynt KE, Jha AK. Thirty-day readmissions: truth and consequences. N Engl J Med. 2012;366:1366-1369.

29. Joynt KE, Jha AK. Characteristics of hospitals receiving penalties under the Hospital Readmissions Reduction Program. JAMA. 2013;309:342-343.

30. Keeney JA, Adelani MA, Nunley RM, Clohisy JC, Barrack RL. Assessing readmission databases: how reliable is the information? J Arthroplasty. 2012;27(8 suppl):72-76.e1-2.

31. Keeney JA, Nam D, Johnson SR, Nunley RM, Clohisy JC, Barrack RL. The impact of risk reduction initiatives on readmission: THA and TKA readmission rates. J Arthroplasty. 2015;30:20572060.

32. Keswani A, Lovy AJ, Robinson J, Levy R, Chen D, Moucha CS. Risk factors predict increased length of stay and readmission rates in revision joint arthroplasty. J Arthroplasty. 2016;31:603-608.

33. Kiridly DN, Karkenny AJ, Hutzler LH, Slover JD, Iorio R, Bosco JA 3rd. The effect of severity of disease on cost burden of 30-day readmissions following total joint arthroplasty (TJA). J Arthroplasty. 2014;29:1545-1547.

34. Kurtz SM, Lau EC, Baykal D, Springer BD. Outcomes of ceramic bearings after revision total hip arthroplasty in the Medicare population. J Arthroplasty. 2016;31:1979-1985.

35. Kurtz SM, Lau EC, Ong KL, Adler EM, Kolisek FR, Manley MT. Which hospital and clinical factors drive 30- and 90-day readmission after TKA? J Arthroplasty. 2016;31:2099-2107.

36. Lavernia CJ, Villa JM, Iacobelli DA. Readmission rates in the state of Florida: a reflection of quality? Clin Orthop Relat Res. 2013;471:3856-3862.

37. Lewinnek GE, Lewis JL, Tarr R, Compere CL, Zimmerman JR. Dislocations after total hip-replacement arthroplasties. $J$ Bone Joint Surg Am. 1978;60:217-220.

38. Lieberman JR, Pensak MJ. Prevention of venous thromboembolic disease after total hip and knee arthroplasty. J Bone Joint Surg Am. 2013;95:1801-1811.

39. Lim SJ, Yeo I, Park CW, Moon YW, Park YS. Outcomes of total hip arthroplasty in patients with primary immune thrombocytopenia. BMC Musculoskelet Disord. 2015;16:278.

40. Martsolf GR, Barrett ML, Weiss AJ, Kandrack R, Washington R, Steiner CA, Mehrotra A, SooHoo NF, Coffey R. Impact of race/ ethnicity and socioeconomic status on risk-adjusted hospital readmission rates following hip and knee arthroplasty. $J$ Bone Joint Surg Am. 2016;98:1385-1391.

41. McNair PD, Luft HS, Bindman AB. Medicare's policy not to pay for treating hospital-acquired conditions: the impact. Health Aff (Millwood). 2009;28:1485-1493.

42. Ninomiya JT, Dean JC, Incavo SJ. What's new in hip replacement. J Bone Joint Surg Am. 2015;97:1543-1551.

43. Nouraie M, Gordeuk VR. Blood transfusion and 30-day readmission rate in adult patients hospitalized with sickle cell disease crisis. Transfusion. 2015;55:2331-2338.
44. Oronce CI, Shao H, Shi L. Disparities in 30-day readmissions after total hip arthroplasty. Med Care. 2015;53:924-930.

45. Parvizi J, Ghanem E, Joshi A, Sharkey PF, Hozack WJ, Rothman RH. Does "excessive" anticoagulation predispose to periprosthetic infection? J Arthroplasty. 2007;22(6 suppl 2):24-28.

46. Parvizi J, Zmistowski B, Berbari EF, Bauer TW, Springer BD, Della Valle CJ, Garvin KL, Mont MA, Wongworawat MD, Zalavras CG. New definition for periprosthetic joint infection: from the Workgroup of the Musculoskeletal Infection Society. Clin Orthop Relat Res. 2011;469:2992-2994.

47. Paxton EW, Inacio MC, Singh JA, Love R, Bini SA, Namba RS. Are there modifiable risk factors for hospital readmission after total hip arthroplasty in a US healthcare system? Clin Orthop Relat Res. 2015;473:3446-3455.

48. Plate JF, Brown ML, Wohler AD, Seyler TM, Lang JE. Patient factors and cost associated with 90-day readmission following total hip arthroplasty. J Arthroplasty. 2016;31:49-52.

49. Pugely AJ, Callaghan JJ, Martin CT, Cram P, Gao Y. Incidence of and risk factors for 30-day readmission following elective primary total joint arthroplasty: analysis from the ACS-NSQIP. $J$ Arthroplasty. 2013;28:1499-1504.

50. Ramkumar PN, Chu CT, Harris JD, Athiviraham A, Harrington MA, White DL, Berger DH, Naik AD, Li LT. Causes and rates of unplanned readmissions after elective primary total joint arthroplasty: a systematic review and meta-analysis. Am J Orthop (Belle Mead NJ). 2015;44:397-405.

51. Saucedo J, Marecek GS, Lee J, Huminiak L, Stulberg SD, Puri L. How accurately are we coding readmission diagnoses after total joint arthroplasty? J Arthroplasty. 2013;28:1076-1079.

52. Schairer WW, Sing DC, Vail TP, Bozic KJ. Causes and frequency of unplanned hospital readmission after total hip arthroplasty. Clin Orthop Relat Res. 2014;472:464-470.

53. Segura JW, Preminger GM, Assimos DG, Dretler SP, Kahn RI, Lingeman JE, Macaluso JN Jr, McCullough DL. Nephrolithiasis Clinical Guidelines Panel summary report on the management of staghorn calculi: the American Urological Association Nephrolithiasis Clinical Guidelines Panel. J Urol. 1994;151:1648-1651.

54. Sellers MM, Merkow RP, Halverson A, Hinami K, Kelz RR, Bentrem DJ, Bilimoria KY. Validation of new readmission data in the American College of Surgeons National Surgical Quality Improvement Program. J Am Coll Surg. 2013;216:420-427.

55. Sibia US, Mandelblatt AE, Callanan MA, MacDonald JH, King PJ (2016) Incidence, risk factors, and costs for hospital returns after total joint arthroplasties. J Arthroplasty. DOI: 10.1016/j. arth.2016.08.003.

56. Silen W, Cope Z. Cope's Early Diagnosis of the Acute Abdomen. New York, NY: Oxford University Press, USA; 2005.

57. Stollman NH, Raskin JB. Diagnosis and management of diverticular disease of the colon in adults: Ad Hoc Practice Parameters Committee of the American College of Gastroenterology. Am J Gastroenterol. 1999;94:3110-3121.

58. Surawicz CM, Brandt LJ, Binion DG, Ananthakrishnan AN, Curry SR, Gilligan PH, McFarland LV, Mellow M, Zuckerbraun BS. Guidelines for diagnosis, treatment, and prevention of Clostridium difficile infections. Am $J$ Gastroenterol. 2013;108:478-498; quiz 499.

59. van Walraven C, Bennett C, Jennings A, Austin PC, Forster AJ. Proportion of hospital readmissions deemed avoidable: a systematic review. CMAJ. 2011;183:E391-402.

60. Voskuijl T, Hageman M, Ring D. Higher Charlson comorbidity index scores are associated with readmission after orthopaedic surgery. Clin Orthop Relat Res. 2014;472:1638-1644.

61. Watts CD, Houdek MT, Wagner ER, Lewallen DG, Mabry TM. Morbidly obese vs nonobese aseptic revision total hip arthroplasty: surprisingly similar outcomes. $J$ Arthroplasty. 2016;31:842-845. 
62. Wera GD, Ting NT, Moric M, Paprosky WG, Sporer SM, Della Valle CJ. Classification and management of the unstable total hip arthroplasty. J Arthroplasty. 2012;27:710-715.

63. Yu S, Garvin KL, Healy WL, Pellegrini VD Jr, Iorio R. Preventing hospital readmissions and limiting the complications associated with total joint arthroplasty. J AmAcad Orthop Surg. 2015;23:e60-71.

64. Zmistowski B, Restrepo C, Hess J, Adibi D, Cangoz S, Parvizi J. Unplanned readmission after total joint arthroplasty: rates, reasons, and risk factors. J Bone Joint Surg Am. 2013;95:1869-1876. 